\title{
Increased spatial-genetic structure in a population of the clonal aquatic plant Sagittaria latifolia (Alismataceae) following disturbance
}

\author{
Ryan Holt ${ }^{1} \cdot$ Allison Kwok ${ }^{1} \cdot$ Marcel E. Dorken $\left(1^{2}\right.$
}

Received: 8 July 2019 / Revised: 2 November 2019 / Accepted: 7 November 2019 / Published online: 11 December 2019

(c) The Author(s), under exclusive licence to The Genetics Society 2019

\begin{abstract}
The spatial genetic structure (SGS) of plant populations is determined by the outcome of key ecological processes, including pollen and seed dispersal, the intensity of local resource competition among newly recruited plants, and patterns of mortality among established plants. Changes in the magnitude of SGS over time can provide insights into the operation of these processes. We measured SGS in a population of the clonal aquatic plant, Sagittaria latifolia that had been disturbed by flooding, both before and after the flood. Over the four-year interval between measurements, we found substantial changes in the magnitude of SGS. In the first measurement (pre-flood), SGS was weak, even over short distances. By contrast, there was substantial SGS in the second measurement (post-flood), particularly over short distances. This change in SGS was accompanied by near complete turnover in the genotypic composition of the population. The genotypic richness of the population (the number of unique clones scaled by the sample size) was halved over the four-year interval. The clonal subrange - the distances between shoots within clones-also shrank considerably, with more than 5\% of shoots having clone-mates at distances $>10 \mathrm{~m}$ before the flood, but fewer than $5 \%$ of shoots having clone-mates at distances beyond $2 \mathrm{~m}$ afterwards. Clonal turnover and the re-establishment of SGS in clonal populations are both expected following local extirpation and recruitment. These data reveal the genetic signatures of disturbance and a subsequent flush of seedling recruitment and clonal expansion.
\end{abstract}

\section{Introduction}

Vascular plants, once established, are immobile but the products of sexual (e.g., pollen, seeds) and, for some plants, asexual propagation (e.g., bulbils, turions) are not. Dispersal of sexual and asexual diaspores at varying distances from source plants results in mosaic patterns of genetic interrelatedness that are expected to differ across species (Vekemans and Hardy 2004). For many plants, dispersal

Supplementary information The online version of this article (https:// doi.org/10.1038/s41437-019-0286-z) contains supplementary material, which is available to authorised users.

Marcel E. Dorken

marceldorken@trentu.ca

1 Environmental and Life Sciences Graduate Program, Trent University, Peterborough, ON K9J 0G2, Canada

2 Department of Biology, Trent University, Peterborough, ON K9J 0G2, Canada distances are limited, with pollen (Austerlitz et al. 2004), seeds (Levin et al. 2003), and clonal propagules (Eckert et al. 2016) dispersing close to the source plant. This spatially-restricted dispersal can result in substantial spatialgenetic structure (SGS), with neighbouring plants more closely related to each other than plants separated by greater distances (Vekemans and Hardy 2004). However, for other plants, SGS is weak and plants are no more likely to be surrounded by relatives than under random dispersal (e.g., González-Martinez et al. 2002). Because SGS reveals the extent to which plants are surrounded by relatives, the magnitude of SGS has important implications for the outcome of key ecological and evolutionary processes, including gene flow, inbreeding, population demography, and ultimately, the evolutionary potential of plant populations.

Substantial SGS arising from spatially-restricted gene dispersal might be compounded for clonal plants, for which the local production of clonal offspring should tend to increase the extent to which plants are surrounded by genetically similar plants. Reproduction, growth, and dispersal in clonal plants result in two distinct types of genetic 
structuring within populations. As for non-clonal plants, spatially-restricted seed dispersal results in local neighbourhoods of related plants (i.e., genets, the genetically unique plants that arise following a bout of sexual reproduction; e.g., Loh et al. 2015). However, clonal expansion and/or the dispersal of clonal fragments and propagules, results in spatial groupings of ramets (the shoots that belong to a genet) that are maximally interrelated; barring somatic mutations they are genetically identical. Mating among these genetically identical ramets could compound the effects of spatially restricted pollen and/or seed dispersal, increasing the effective magnitude of SGS (Scofield and Schultz 2005).

The habitats in which plants occur should have important implications for the magnitude of SGS. In particular, rates of disturbance, recruitment, and the presence of habitatspecific vectors of dispersal should have profound effects on patterns of SGS (Vekemans and Hardy 2004). Aquatic habitats have several features that should affect the magnitude of SGS (reviewed by Eckert et al. 2016). First, unlike terrestrial plants, aquatic plants are surrounded by an important vector of dispersal-water. Second, aquatic plants should often be subject to non-random (directed) patterns of dispersal, with water currents or other vectors of dispersal (e.g., water fowl) tending to disperse propagules to other aquatic habitats more often than would be expected under random, isotropic dispersal (e.g., Purves and Dushoff 2005). Finally, wetlands-particularly those subject to regular or sudden hydrological changes (e.g., tidal wetlands, river and stream margins) — can be highly dynamic with effects on the spatial genetic structure of plant populations (e.g., Kamel et al. 2012; Tero et al. 2005; Pollux et al. 2007). For all of these reasons, we might expect aquatic plants to have lower SGS than terrestrial plants, and the limited data available are consistent with this expectation (Eckert et al. 2016).

Patterns of SGS should depend on a variety of population-specific processes (rates of disturbance, patterns of clonal growth, habitat-specific vectors of dispersal) that are contingent, in part on the history of colonisation, recruitment, and growth within each population. In particular, patterns of SGS should tend to fluctuate over time in response to processes affecting dispersal, establishment and colonisation; processes such as disturbance, opportunities for clonal versus sexual recruitment, and the competitive displacement of genets. Although the repeated measure of SGS in the same population at different points in time has rarely been conducted, in one such example the magnitude of SGS increased after a bout of seed recruitment that followed a major disturbance event in a population of the shrub Persoonia mollis (Ayre et al. 2009).

The purpose of this study was to quantify temporal changes in SGS in a population of the clonal emergent aquatic plant Sagittaria latifolia Willd. (Alismataceae) over a 4-year interval. It was motivated by the observation made while conducting a study of mating patterns in a population of S. latifolia in 2013 (Stephens et al. 2019, Patterns of pollen dispersal and mating in a population of the clonal plant Sagittaria latifolia (unpublished)). At that time we noticed that, at the end of the growing season, a new beaver dam had raised water levels in the site by more than $0.5 \mathrm{~m}$. By 2016 water levels had returned to levels characteristic of the site in 2013 but there were many fewer plants than in 2013. We were therefore interested in evaluating whether genets present in 2013 had survived the flooding event, and if there was evidence for genet mortality, whether clonal turnover was associated with changes to the spatial-genetic structure of the population. Accordingly, we compared the magnitude of SGS at each point in time to the range of estimates reported for this species and used this information to make inferences about clonal turnover and genet recruitment. In particular, because clonal growth in S. latifolia is associated with the annual death of ramets, the production of overwintering structures at the ends of stolons, and opportunities for the dispersal of clonal disapores, clonal growth should tend to reduce the magnitude of SGS over time, as genets become displaced from their site of origin. Because $S$. latifolia is tolerant of flooding, at least under controlled conditions (Kenow et al. 2018), we expected population recovery via the regrowth of plants from perennating ramets and therefore a reduction in the magnitude of SGS from 2013 to 2017.

\section{Materials and methods}

\section{Study species}

Sagittaria latifolia Willd. is an emergent clonal aquatic plant common to a variety of wetland habitats in North America. Populations of S. latifolia may be either monoecious (i.e., populations of hermaphrodites with unisexual female or male flowers) or dioecious (i.e., populations of plants with separate sexes-whole plants are either female or male) and sex is determined by the segregation of alleles with simple Mendelian inheritance (Dorken and Barrett 2004). Most populations in the study region, including the one studied here, are monoecious. Populations of S. latifolia are subject to frequent population turnover, particularly monoecious populations, which are more commonly found in disturbance-prone habitats than dioecious populations (Dorken and Barrett 2003). Compared with dioecious populations, monoecious populations more often occur in sites with flowing water (including the site studied here) and in the absence of other large aquatic macrophytes such as cattails. 
Clonal growth in S. latifolia occurs via the sprouting of daughter ramets at the terminal end of axillary stolons during the early part of the growing season and via the production of corms in late summer, after peak flowering. Corms enable the overwinter survival of genets; all other vegetative tissues die back in the autumn. Because corms can float, the disintegration of solons can enable the dispersal of corms in habitats with flowing water. For this reason, and because corms are produced some distance away from the parent ramet, the location of genets shifts over time. Although S. latifolia is capable of rapid clonal growth (Dorken and Barrett 2003), natural populations tend to be clonally diverse (Yakimowski and Barrett 2014).

Seedling recruitment and establishment of S. latifolia in natural populations have not been reported. However, controlled conditions mimicking those that occur in nature yield in high rates of germination on exposed (Dorken and Barrett 2003) and flooded soils (Schorg and Romano 2018), and regeneration from soil seed banks has been reported (Kenow and Lyon 2009). Under greenhouse conditions, seedlings flower and produce multiple clonal diaspores in their first year of growth (Dorken and Barrett 2003).

Monoecious $S$. latifolia are self-compatible and high rates of selfing are found in some populations (Dorken et al. 2002). However, the magnitude of the inbreeding coefficient is low across populations (Dorken et al. 2002), suggesting that selfing, even though it can occur, does not strongly contribute to patterns of SGS. Flowering by $S$. latifolia is size-dependent (Sarkissian et al. 2001) and although the proportion of flowering ramets varies across sites, observations from dozens of sites in the study region indicate that most ramets arising from overwintering corms go on to produce flowers (Dorken et al. 2002; Dorken and Mitchard 2008). Peak flowering in our region occurs in July and female flowers produce hundreds of unfused achenes (hereafter referred to as seeds). Seeds may be dispersed by water currents and dispersal by animals (which has been studied for the congener S. sagittifolia; Pollux et al. 2005, 2006) might also be possible.

\section{Sampling}

We investigated a monoecious population of $S$. latifolia located close to Trent University that occupied a shallow area of Thompson Creek in Meadowvale Park, Peterborough, Ontario (44.3333N, 78.3126W). Flowering ramets were patchily distributed over an area of $\sim 25 \mathrm{~m} \times 60 \mathrm{~m}$ and isolated from other populations of $S$. latifolia by at least $100 \mathrm{~m}$. Between June and September 2013, we visited the site daily between the start of flowering in June to the end of flowering in September to record the number and sex of flowers produced on each flowering ramet. A total of 506 flowering ramets were tagged and a sample of leaf tissue from the youngest leaf per ramet was taken for subsequent DNA extraction. After flowering had finished all ramets were mapped using triangulation (e.g., Ahee et al. 2014). To do this, we placed reference points (6-ft. lengths of rebar, positioned vertically in the stream bed) along the central channel of the creek. We followed the same procedure in 2017, sampling all flowering ramets. The ramets present in the population in 2017 occupied a subset of the area occupied in 2013. The population was therefore substantially smaller in 2017 than in 2013 (both in terms of the area spanned by $S$. latifolia and in terms of the number of ramets) and only 189 ramets were sampled in 2017 . However, the reference points used to assist triangulation were removed when mapping was completed in 2013 and so different reference points were used for mapping in 2017. Although this made it impossible to determine the extent to which clones had shifted positions between the two samples, as shown in the results, only one multi-locus genotype from 2013 was recovered in our 2017 sample.

\section{SSR genotyping}

Each leaf sample was ground into a powder using a MM 300 Retsch mixer mill (Haan, Germany) and DNA was extracted using E.Z.N.A. Plant DNA Kits (Omega BioTek., Inc., Georgia, USA). DNA concentrations were quantified using fluorometric quantitation. DNA samples were diluted to a standardised concentration of $50 \mathrm{ng} / \mu \mathrm{l}$. Nine SSR loci were amplified using fluorescently tagged primers following the methods of Yakimowski et al. (2009) (using loci SL06, SL21, SL27, SL65, SL74, SL75, and SL88) using the following modifications: Four nuclear SSR microsatellite loci (SL65, SL06, SL75 and SL27) were amplified individually and five loci (SL30, SL88, SL21, SL09, SL74) were amplified in two multiplexes using fluorescently tagged primers. For individual reactions the PCR master mix contained $0.2 \mu \mathrm{M}$ of forward and reverse primer, $0.15 \mathrm{mM}$ dNTPs, $1 \mathrm{X}$ buffer, $2 \mathrm{mM} \mathrm{MgCl}_{2}, 0.3 \mathrm{mM}$ BSA and $0.05 \mathrm{U} / \mathrm{rxn}$ Taq DNA Polymerase (Invitrogen, Waltham, MA, USA). DNA amplification was conducted using Eppendorf Mastercycler ${ }^{\circledast}$ thermal cyclers (Eppendorf, Germany). Cycle conditions were as follows: denaturing at $94{ }^{\circ} \mathrm{C}$ for $3 \mathrm{~min}$, amplification repeated for 30 cycles of $94{ }^{\circ} \mathrm{C}$ for $30 \mathrm{~s}$, annealing at $60-62^{\circ} \mathrm{C}$ for $30 \mathrm{~s}$ and $72{ }^{\circ} \mathrm{C}$ for $45 \mathrm{~s}$, with a final elongation at $72^{\circ} \mathrm{C}$ for $45 \mathrm{~min}$. All primers had an annealing temperature of $60^{\circ} \mathrm{C}$, except for SL65, which was annealed at $62{ }^{\circ} \mathrm{C}$. Multiplex 1 contained SL21 forward and reverse primers at concentrations of $0.1 \mu \mathrm{M}$ and SL30 had primer concentrations of $0.19 \mu \mathrm{M}$; the rest of the reaction mixture contained $0.15 \mathrm{mM}$ dNTPs, $1 \times$ buffer, $1.3 \mathrm{mM} \mathrm{MgCl}, 0.3 \mathrm{mM}$ BSA, and 0.5 U/rxn GoTaq Flexi DNA polymerase (Promega, Madison, WI, USA). Multiplex 2 contained SL88 forward and reverse primers at 
concentrations of $0.18 \mu \mathrm{M}$, SL09 primers at concentrations of $0.1 \mu \mathrm{M}$, and SL74 primer concentrations of $0.16 \mu \mathrm{M}$ with the remaining reaction mixture containing $0.15 \mathrm{mM}$ dNTPs, $1 \times$ buffer, $1.6 \mathrm{mM} \mathrm{MgCl}, 0.3 \mathrm{mM}$ BSA and $0.5 \mathrm{U} / \mathrm{rxn}$ GoTaq Flexi DNA polymerase (Promega, Madison, WI, USA). Amplification for multiplexes involved initial denaturation at $94{ }^{\circ} \mathrm{C}$ for $3 \mathrm{~min}, 25$ cycles of $94{ }^{\circ} \mathrm{C}$ for $45 \mathrm{~s}$, annealing at $57^{\circ} \mathrm{C}$ for multiplex 1 and $56.5^{\circ} \mathrm{C}$ for multiplex 2 for $45 \mathrm{~s}$ and $72{ }^{\circ} \mathrm{C}$ for $45 \mathrm{~s}$, and a final elongation at $72{ }^{\circ} \mathrm{C}$ for $10 \mathrm{~min}$. The quality of amplification products was evaluated on an agarose gel and then diluted $20 \times$ using $\mathrm{ddH}_{2} \mathrm{O}$. Then $0.7 \mu \mathrm{l}$ of this dilution was mixed with $9 \mu \mathrm{l}$ of HiDi containing ROX 500 size standard (Applied Biosystems, Waltham, MA, USA) and run on an ABI3730 (Applied Biosystems, Waltham, MA, USA). Genotypes were scored using Genemarker ${ }^{\bullet}$ software (v 1.6; Softgenetics). Ten percent of samples were re-amplified, genotyped and the resulting allele scores compared to the originals using GIMLET (v. 1.3.3, Valière 2002). The presence of null alleles was examined using CERVUS ( $\mathrm{v}$ 3.0.7, Kalinowski et al. 2007). Two loci (SL09 and SL30) were subject to higher frequencies of scoring errors and null alleles. These loci were discarded from our analyses.

\section{Data analysis}

\section{Genetic and genotypic diversity}

Because ramets from the same genet can have slightly different MLGs (because of scoring errors and/or somatic mutations; Schnittler and Eusemann 2010), we grouped MLGs into multi-locus lineages that differed by up to two allelic differences. This value was determined by visualising pairwise genetic differences, calculated using the genet_dist and genet_dist_sim functions from the RClone package (v. 1.0.2, Arnaud-Haond and Bailleul 2016) in R (v. 3.6.0, R Core Team 2019). The genetic distances calculated using the genet_dist function were then used to assign ramets to MLLs using the MLG_list and MLL_generator2 functions in RClone. For each year, we calculated the probabilities that ramets with the same multi-locus genotype (MLG) were the products of independent mating events using the psex_Fis function from the RClone package. Across both samples, only two of 695 ramets had values of $P_{-}$sex greater than 0.05. MLL assignment joined one of these ramets into a MLL comprising two MLGs. For our analyses, therefore, we assumed that all MLLs were the products of separate mating events.

We evaluated changes in allele frequencies of MLLs for each locus in each sample using the freq_RR function from the RClone package and then examined the correspondence in allele frequencies across the two samples by calculating the Pearson correlation coefficient using the $\mathrm{lm}$ function in
R. We calculated allelic diversity, Nei's (1978) gene diversity and observed heterozygosity at the MLL level for each sample year from genind objects generated using the df2genind function from the adegenet package (Jombart 2008). We examined changes in the inbreeding coefficient between sample years by calculating per-locus values of $F_{\text {IS }}$ for MLLs using the Fis function from the RClone package.

\section{Clone structure and diversity}

We evaluated changes in patterns of clonal diversity between samples by examining the Pareto distribution using the Pareto_index function from the RClone package. In particular, comparison of the slope of the Pareto distribution between samples indicates changes in patterns of clonal diversity in the population, with higher values of the slope parameter indicating greater evenness of clone size distributions (i.e., higher values occur in populations with a more even distribution of clone sizes, measured as the number of ramets per MLL; Arnaud-Haond et al. 2007). For each year of sampling we calculated genotypic (MLL) richness as $R$ (Dorken and Eckert 2001) using the clona1_index function in RClone. Values of $R$ range between 0 (when all ramets belong to the same clone) and 1 (when all ramets belong to different clones; i.e., the population is not clonal). The magnitude of spatial clustering of MLLs was calculated using the aggregation index $\left(A_{c}\right.$; Arnaud-Haond et al. 2007), which estimates the relative probability that ramet pairs that are nearest neighbours belong to the same MLL versus the average probability that ramet pairs belong to the same MLL using the agg_index function in RClone. Values for $A_{\mathrm{c}}$ range between 0 (when clones are not spatially aggregated) and 1 (when clones are highly clumped). The area occupied by genets within the population was estimated by calculating the area of the convex hull around all ramets in the 2013 and 2017 samples using the chull and Polygon functions from the base R (R Core Team 2019) and sp (v. 1.3-1, Pebesma and Bivand 2005; Bivand et al. 2013) packages, respectively.

\section{Spatial genetic structure}

We evaluated spatial genetic structure in two ways. First, we evaluated spatial autocorrelations in kinship by calculating the value of the Loiselle coefficient (Loiselle et al. 1995) among pairs of ramets from different MLLs at 2-m distance intervals using the autocorrelation function in the RClone package. For each sample year we used a combination of permutation tests to evaluate significant departures from the null expectation and bootstrapping for visualisation of the effect of ramet choice on the magnitude of any calculation of spatial autocorrelation. We calculated the proportion of ramets belonging to the same MLL at 2-m 
intervals using the clonal_sub function from the RClone package.

Second, we evaluated overall changes in SGS by calculating the $S p$ statistic (Vekemans and Hardy 2004). This statistic describes changes in the degree of kinship among plants with distance and is useful for comparing patterns of SGS across populations and species (Vekemans and Hardy 2004). The $S p$ statistic is a measure of the degree to which genotypes (i.e., in our case different clones) are nonrandomly distributed, and calculations of $S p$ require the use of a single location per genotype. For clonal plants, there are two alternatives for the choice of genotype location: the MLL centroid or a resampling approach in which a single ramet per MLL and its location are randomly chosen in repeated permutations (Alberto et al. 2005). The centroid approach assumes isotropic growth from a central location (the birthplace of the genet) without disturbance or dispersal of clonal fragments. These assumptions do not hold for $S$. latifolia. Accordingly, we used a resampling approach to calculate values of the $S p$ statistic for 2013 and 2017. In particular, we generated 1000 resampled datasets for each sample year, with each dataset including one randomly selected ramet per MLL. The 1000 resampled sets were input into the software SPAGeDI (Hardy and Vekemans 2002) to calculate the $S p$ statistic for each resampled dataset using an AutoHotkey (v. 1.1.30.01, AutoHotkey Foundation LLC) script to automatically run repeated instances of the SPAGeDi programme. For each run, we specified the calculation of kinship coefficients at the individual level, the use of the Loiselle kinship coefficient, and the use of restricted regression analyses (with minimum and maximum distances of 0 and $5 \mathrm{~m}$ ). $S p$ was calculated as $S p=$ $\widehat{b}_{f} /\left(1-\widehat{F}_{(1)}\right)$, where $\widehat{b}_{f}$ is the slope of the regression of the mean pairwise kinship coefficients on the logarithm of the distance between ramets, and where $\widehat{F}_{(1)}$ is the mean pairwise kinship coefficient in the first distance interval (Vekemans and Hardy 2004). Distance classes were designated as: $1.13,2,4,6,8,10,12,14,16,18 \mathrm{~m}$. The first distance class $(1.13 \mathrm{~m})$ was based on a calculation of the average nearest neighbour-distance between genets. Variance among the 1000 random resamples used to calculate mean $S p$ provided a measure of the confidence in the value calculated in each case.

\section{Results}

\section{Turnover of genets between 2013 and 2017}

Overall patterns of genetic variation in the two samples were largely unchanged, with similar values for mean allelic richness (2013: $7.57 \pm 3.69 \mathrm{SD} ; 2017: 8.57 \pm 3.41 \mathrm{SD})$ and Nei's (1978) gene diversity (2013: $0.59 \pm 0.26$; 2017 :
$0.60 \pm 0.24 \mathrm{SD})$. There was a strong correlation between allele frequencies in 2013 and in 2017 (Pearson's $r=0.77$, $\mathrm{df}=75, P<0.001)$. Although the numbers of MLLs shrank by more than half from 169 in 2013 to 80 in 2017, patterns of clone-size diversity, measured as the slope of the Pareto distribution, were similarly skewed towards smaller clones in both sample years $(-\beta$ 2013: $0.69 ;-\beta$ 2017: 0.61 ; and see Fig. 1, Fig. S1). In both years, clones were moderately spatially aggregated $\left(2013 A_{\mathrm{c}}=0.30 ; 2017 A_{\mathrm{c}}=0.34\right)$.

In spite of the relatively static distributions of alleles and clone sizes in the population, there was a nearly complete turnover of genets between samples; only one MLG from the 2013 sample was detected in the 2017 sample. At the same time, the size of the population, in terms of the area occupied by the sampled ramets, shrank by $81 \%$ (from 1015 to $193 \mathrm{~m}^{2}$; Fig. 1), genotypic richness increased by $27 \%$ (from 0.33 to 0.42 ) and the inbreeding coefficient $\left(F_{\mathrm{IS}}\right)$ increased by an order of magnitude (from $<0.01 \pm 0.12 \mathrm{SD}$ in 2013 to $0.15 \pm 0.17 \mathrm{SD}$ in 2017). This increase in the inbreeding coefficient was mirrored by a decrease in observed heterozygosity from 2013 (average $H_{\mathrm{O}}=0.57 \pm$ $0.25 \mathrm{SD}$ ) to 2017 (average $H_{\mathrm{O}}=0.51 \pm 0.20 \mathrm{SD}$ ).

\section{Change in spatial-genetic structure between 2013 and 2017}

The spatial genetic structure of the population changed substantially over the four-year period. In 2013 there was no overall pattern of changes in kinship with distance, but in 2017 pairwise kinship decreased from a mean value of 0.12 over distances up to $1.5 \mathrm{~m}$ to near 0 at distances over $3 \mathrm{~m}$. At larger spatial scales, kinship declined from near 0 at distances of $15 \mathrm{~m}$ to -0.10 at distances of $20 \mathrm{~m}$ (Fig. 2). This change in the genetic structure of the population over time was reflected by changes in the values of the $S p$ statistic, which — and contrary to our prediction —increased by an order of magnitude between 2013 and 2017 (2013: $S p=$ $4.3 \times 10^{-3}$, range: $3.2 \times 10^{-3}-5.8 \times 10^{-3} ; 2017: S p=4.7 \times$ $10^{-2}$, range: $4.1 \times 10^{-2}-5.3 \times 10^{-2}$ ). Clone sizes, and the spatial scales spanned by clones in particular, shrank at the same time that genetic structure increased in magnitude. In 2013 the clonal subrange often extended beyond $10 \mathrm{~m}$ (Fig. $3 a)$, but in 2017 the vast majority of ramets separated by $\geq 10 \mathrm{~m}$ were from different MLLs (Fig. 3b).

\section{Discussion}

Over a four-year period, we observed a substantial increase in spatial-genetic structure that coincided with nearly complete clonal turnover. The new clones in the 2017 sample were smaller than in 2013, more genotypically diverse, and more likely to be related to one another, 


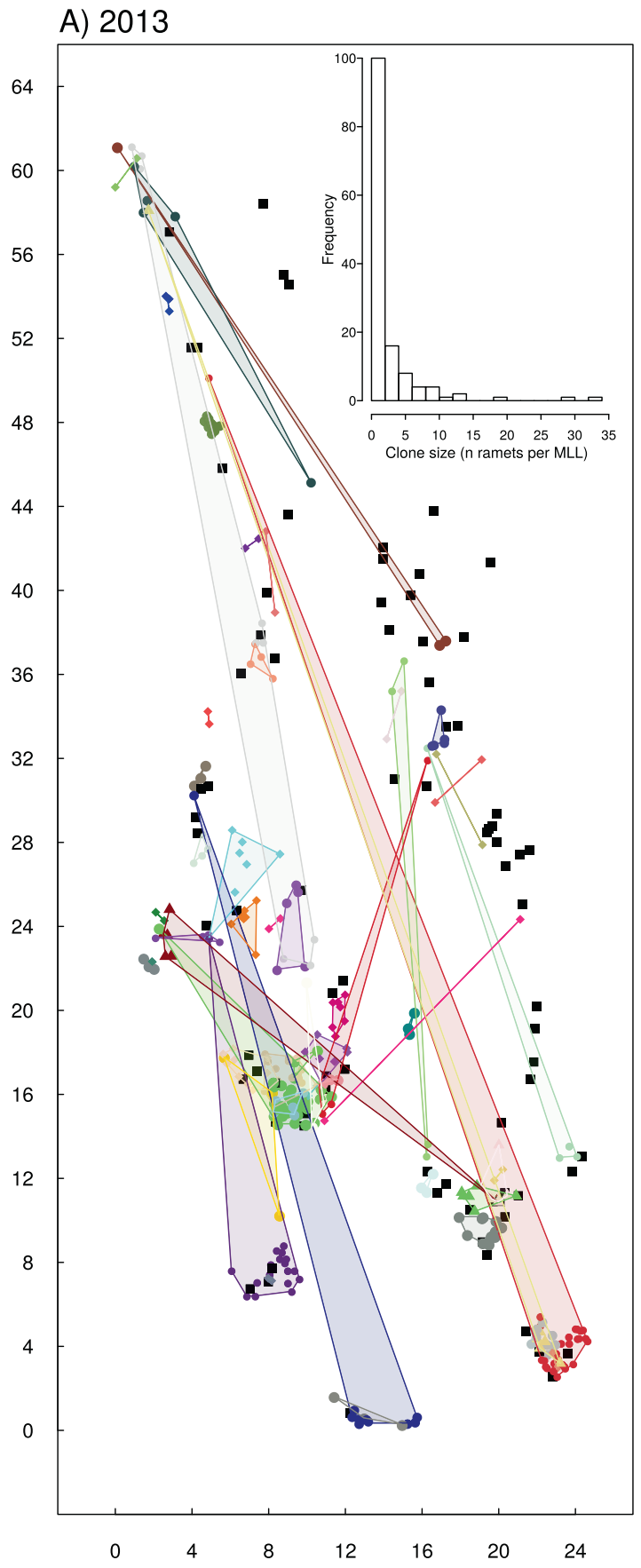

Fig. 1 Maps of the distributions of genets in each year of sampling. Maps of the population in 2013 (a) and 2017 (b). Ramets sharing the same colour and symbol (and bounded by a convex hull) in each year indicate the position of genets (MLLs). Only one MLL from the 2013 sample was recovered in 2017. This MLL occurred in roughly the same part of the population in both years but because we used different reference points for mapping in each year, the extent to which this MLL might have changed positions cannot be determined (in 2013 this MLL is represented by seven ramets and indicated by the combination of the colour "deep pink" and the diamond symbol, located at

particularly if they occurred close to one another. As argued below, these changes in the genetic and genotypic structure of the population are consistent with the occurrence of one
B) 2017

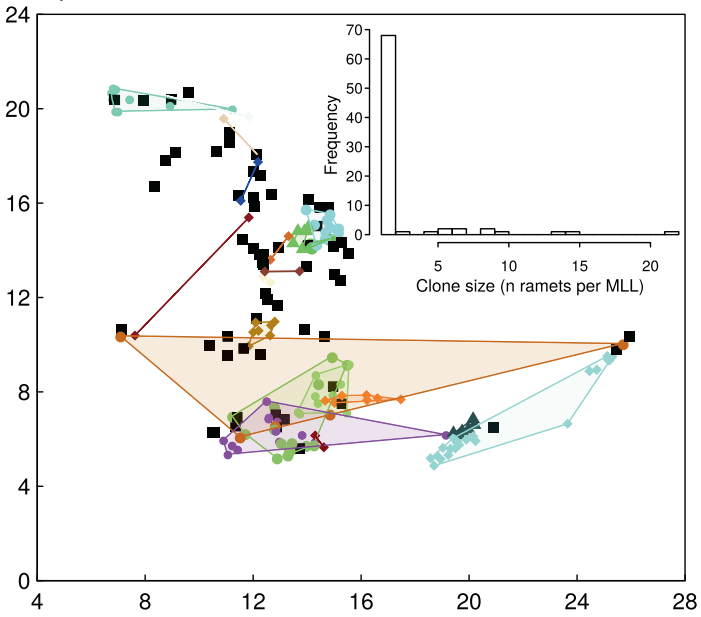

roughly $x=12 \mathrm{~m}, y=20 \mathrm{~m}$; in 2017 the MLL was represented by a single ramet and indicated on the map by a black square at $x=6.3 \mathrm{~m}$, $y=10.6 \mathrm{~m}$ ). Note that because we used a restricted colour and symbol palette, there are instances of different MLLs sharing the same colour and symbol combination, however ramets from the same MLL are always enclosed by (or for smaller MLLs, joined by) a convex hull. Axis scales in metres. The insets in each panel indicate the frequency distribution of clone sizes in each year. All ramets sampled in 2017 occurred approximately in the area corresponding to $x=0-20, y=$ $12-32$ in a.

or more episodes of seedling recruitment between 2013 and 2017. Seedling recruitment for some aquatic plants is known to be episodic (e.g., swamp paperbark, Melaleuca 

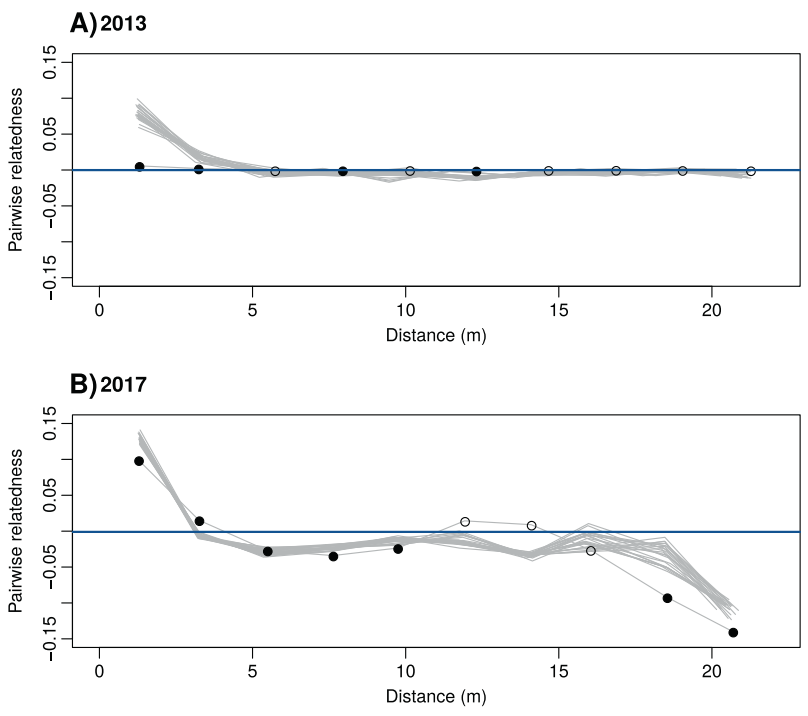

Fig. 2 Spatial autocorrelation in pairwise (Loiselle) kinship between genets (MLLs) in each year of sampling. Spatial autocorrelation in pairwise (Loiselle) kinship between genets (MLLs) in 2013 (a) and 2017 (b). Black circles indicate significant spatial autocorrelations that could be either positive (for points above the horizontal line in each plot) or negative (for points below the line). Levels of significance were calculated using permutation tests in which ramets were randomly resampled from each MLL using the nbrepeat option in the autocorrelation function in RClone (Arnaud-Haond and Bailleul 2016). Grey lines indicate the results of 25 bootstrapped autocorrelation tests; in each bootstrapped run a single, randomly chosen ramet was selected to represent each MLL. These lines are provided to enable visualisation of how the selection of ramets to represent MLLs affected the inferred magnitude of spatial autocorrelations in relatedness. Mean kinship values for each sample year are indicated by a blue horizontal line.

ericifolia, Robinson et al. 2008) and hydrological changes to wetlands are linked to clonal turnover and local extinction events (de Ridder and Dhondt 1992). The sudden change in water levels that coincided with rapid clonal turnover and the re-establishment of new genets is consistent with episodic recruitment for S. latifolia, at least for this population over the four-year period examined here. Monoecious populations of $S$. latifolia are known to be subject to regular population turnover events (Dorken and Barrett 2003). Although this did not occur here-at least one clone appears to have survived the disturbance eventour data reveal the genetic signature of a major disturbance to the population and its subsequent recovery through seed germination.

We were surprised that nearly all of the genets sampled in 2013 were absent from the 2017 sample of the population. Although it is possible that our sampling strategy resulted in the omission of a small number of genets, incomplete sampling cannot explain the absence of nearly all 2013 genets in our 2017 sample. Even if some ramets emerging from overwintering corms failed to flower, we expect most ramets to reach sufficient size to produce

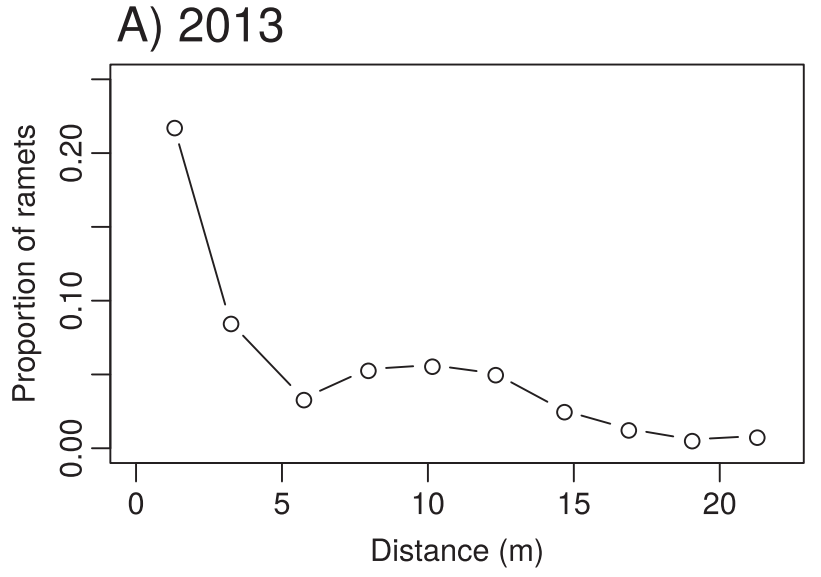

B) 2017

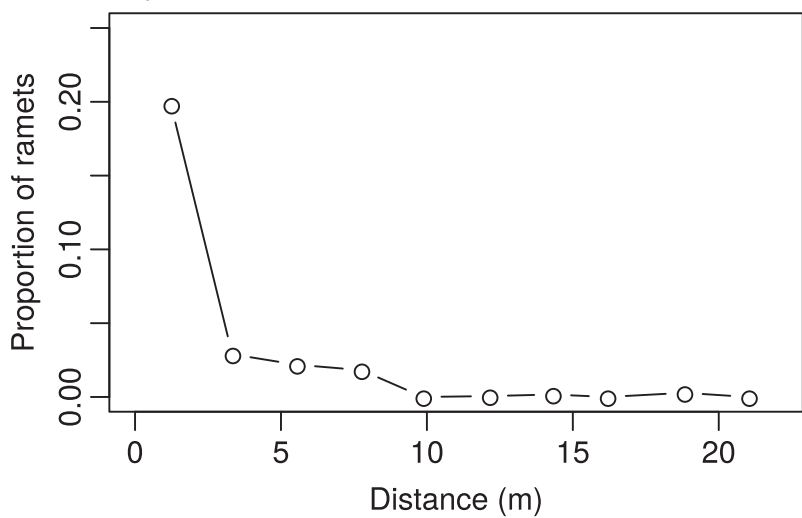

Fig. 3 Plots of the clonal subrange across distance classes in each year of sampling. Plots of the clonal subrange across distance classes in 2013 (a) and 2017 (b). The clonal subrange is determined by the proportion of ramets from a single genet (MLL) that are separated by a given distance. For example, for the 2013 sample, 5\% of ramets separated by $10 \mathrm{~m}$ belong to the same MLL.

flowers and therefore be represented in our sample; even under stressful, nutrient-starved conditions, more than half of ramets from monoecious populations will produce flowers (unpublished data from Dorken and Mitchard 2008). Clonal growth is often invoked as a mechanism that promotes genet survival by spreading the risk of mortality across numerous ramets. Sagittaria latifolia is often found in disturbed aquatic habitats, such as road-side ditches and ice-scoured lake margins, ramets within genets can be widely separated (as shown in Fig. 1a) and unless disturbances affect the entire wetland, we expect some ramets to survive periodic disturbances. In some ecosystems, clonal plants can clearly survive over long periods of time (Kemperman and Barnes 1976; Berković et al. 2018), however, rates of clonal turnover in aquatic ecosystems have not been extensively studied. A multi-year study of long-leaved sundew (Drosera intermedia) showed that changes in water levels were associated with genet turnover and local extinction events (de Ridder and Dhondt 1992). 
Our data similarly indicate the importance of changes to water levels for genet survival.

The genets in our 2017 sample that did not occur in the population in 2013 must have arisen from seeds and/or the immigration of clonal propagules from other populations. The dispersal of clonal fragments and corms is possible and has been inferred from genetic data for other aquatic plants (e.g., Phragmites australis, Kirk et al. 2011; Posidonia oceanica, Diaz-Almela et al. 2007). Indeed, the disjunct distribution of some MLLs is consistent with the dispersal of clonal fragments within the population. Although we cannot rule out the occurrence of some genet establishment via the immigration of clonal propagules, this process cannot explain our observations on their own. First, although corms of $S$. latifolia can float, we have rarely observed corm dispersal in natural populations and it seems unlikely that the entire population would have been recolonised by clonal fragments originating from other populations; the population studied here was isolated from other populations of S. latifolia by at least $100 \mathrm{~m}$. Second, and more to the point, the dispersal of corms into the population over long distances could not result in the establishment of spatial-genetic structure, which arises from spatiallyrestricted gene dispersal. Therefore, even if some of the genets in our 2017 sample arose from the dispersal of corms from other populations, the existence of spatial-genetic structure in 2017 indicates that many of the extant genets arose following local seed dispersal.

Our measure of spatial-genetic structure for the 2013 sample was remarkably similar to the global mean from 10 monoecious populations of $S$. latifolia studied by Yakimowski and Barrett (2014) (reported mean $S p=4.0 \times$ $10^{-3}$, similar to our value of $4.3 \times 10^{-3}$ ). However, our measure of $S p=0.047$ for 2017 was greater than any of their estimates from monoecious populations (maximum reported value for monoecious populations from Yakimowski and Barrett 2014; $S p=0.015$ ) and dioecious populations (maximum reported value for monoecious populations from Yakimowski and Barrett 2014; $S p=$ 0.036). The spatial-genetic structure of our population was therefore typical for S. latifolia in 2013, but not in 2017. In comparison with the 47 species for which measures of $S p$ were compiled by Vekemans and Hardy (2004), our measures of $S p$ for 2013 ranks among species with the least spatial-genetic structure, but for 2017 among species with most spatial-genetic structure. Over the four years that elapsed between sampling events there has clearly been a regime shift in the spatial-genetic structure of the population.

Because SGS arises through limited gene dispersal, the relatively high degree of SGS in 2017 implies limits to seed and possibly pollen dispersal. For this population, we have inferred that pollen is often dispersed over distances greater than $10 \mathrm{~m}$ (Stephens et al. 2019, Patterns of pollen dispersal and mating in a population of the clonal plant Sagittaria latifolia (unpublished)). Therefore, considering the scale over which we detected spatial-genetic structure it seems more likely that SGS arose via spatially-restricted seed dispersal. Seed dispersal for S. latifolia entails the dropping of seeds from their receptacle either into water, or, for emergent plants, onto the ground below the plant. The magnitude of SGS in the population in 2017 was similar to that observed for non-clonal, terrestrial plants with gravity and/or animal seed dispersal (reviewed in Vekemans and Hardy 2004). We did not observe seed dispersal directly, but, taken together, the magnitude of SGS in this population in 2017 was consistent with the simple gravity dispersal of seeds onto exposed substrates. Indeed, the plants comprising the population in 2017 were clustered around an exposed part of the wetland that was dominated by grasses in 2013. Although the broad geographic distributions for most aquatic plants, including $S$. latifolia, is indicative of frequent long-distance dispersal (Santamaría 2002; Viana et al. 2013), the distribution of seed dispersal distances, have rarely been evaluated for aquatic plants ( $\mathrm{Li} 2014$; de Jager et al. 2019). Because S. latifolia normally grows in water, seeds should normally be secondarily dispersed by water, enabling dispersal over a broad range of distances. If so, SGS should normally be weak in populations of $S$. latifolia, which it usually appears to be.

Weak SGS in S. latifolia, including our 2013 sample, may also arise via repeated rounds of clonal growth and the competitive exclusion of genets. Clonal growth in S. latifolia entails the movement of genets over time; ramets are annual and perennating structures are placed some distance away from the source ramet. The survival of genets over time should therefore result in the outward expansion of genets and/or the movement of genet centroids. Because we do not expect this movement to be anisotropic, clonal growth should tend to reduce the magnitude of SGS by displacing genets from their site of origin. Moreover, competitive exclusion, particularly of inbred genets, should be associated with increased heterozygosity and lower measures of the inbreeding coefficient. Levels of observed heterozygosity were lower in 2017 than in 2013 and this change coincided with a large increase in the inbreeding coefficient. Clonal plant populations often maintain high levels of heterozygosity (Ellstrand and Roose 1987). Indeed, a positive association between clone size and heterozygosity found in some plants (Hämmerli and Reusch 2003) has been argued to reflect better growth performance of outbred versus inbred genets. For Spartina alterniflora the association between clone size and heterozygosity is only apparent in older wetlands, implying that this association takes time to develop (Travis and Hester 2005). If seedling recruitment is followed by the competitive 
replacement of inbred and more homozygous clones, then higher levels of homozygosity in younger versus older populations are expected. Although we cannot know the age of the genets present in 2013, the larger size of the clones and the greater area occupied by them suggests that clones were older in 2013 than in 2017. If so, the increase in the inbreeding coefficient and the coinciding drop in observed heterozygosity from 2013 to 2017 are consistent with this expectation.

Our data add to the scant information on the spatialgenetic structure of aquatic plants (Eckert et al. 2016). We showed that SGS is not a static feature of populations and can change dramatically over short periods of time. If our 2013 sample represents a more established population-as evidenced from our measure of SGS closely aligning with the mean value from measures of 20 populations (Yakimowski and Barrett 2014) and our 2017 sample reflects the SGS that arises shortly after one or more bouts of seedling recruitment, then our results provide insights into the temporal trajectory of SGS. In particular, genet survival and expansion, together with competitive exclusion should weaken patterns of SGS over time. Indeed, this trajectory in SGS is not unique to $S$. latifolia; such patterns also emerge in comparisons of SGS between seedling and mature cohorts of plants (e.g., González-Martinez et al. 2002). Thus, we expect this pattern to hold for other populations of $S$. latifolia, and, indeed for other clonal plants for which genet survival also entails the movement of genets and/or the competitive exclusion of plants within populations.

\section{Data availability}

Data available from the Dryad Digital Repository: https:// doi.org/10.5061/dryad.cc2fqz62r

Acknowledgements We thank J. Houpt for assistance in the field and in the laboratory, J. Freeland for thoughtful comments on an earlier draft of this manuscript and the Natural Sciences and Engineering Research Council of Canada (NSERC) for undergraduate student research awards to J. Houpt and R. Holt, and for a Discovery Grant to M. Dorken.

\section{Compliance with ethical standards}

Conflict of interest The authors declare that they have no conflict of interest.

Publisher's note Springer Nature remains neutral with regard to jurisdictional claims in published maps and institutional affiliations.

\section{References}

Ahee JE, Van Drunen WE, Dorken ME (2014) Analysis of pollination neighbourhood size using spatial analysis of pollen and seed production in broadleaf cattail (Typha latifolia). Botany 93:91-100

Alberto F, Gouveia L, Arnaud-Haond S, Pérez-Lloréns JL, Duarte CM, Serrão EA (2005) Within-population spatial genetic structure, neighbourhood size and clonal subrange in the seagrass Cymodocea nodosa. Mol Ecol 14:2669-2681

Arnaud-Haond S, Duarte CM, Alberto F, Serrão EA (2007) Standardizing methods to address clonality in population studies. Mol Ecol 16:5115-5139

Arnaud-Haond S, Bailleul D (2016) RClone: partially clonal populations analysis. R package version 1.0.2. https://CRAN.R-project. org $/$ package $=$ RClone

Austerlitz F, Dick CW, Dutech C, Klein EK, Oddou-Muratorio S, Smouse PE, Sork VL (2004) Using genetic markers to estimate the pollen dispersal curve. Mol Ecol 13:937-954

Ayre DJ, Ottewell KM, Krauss SL, Whelan RJ (2009) Genetic structure of seedling cohorts following repeated wildfires in the fire-sensitive shrub Persoonia mollis ssp. nectens. J Ecol 97:752-760

Berković B, Coelho N, Gouveia L, Serrão EA, Alberto F (2018) Individual-based genetic analyses support asexual hydrochory dispersal in Zostera noltei. PLOS One 13:e0199275

Bivand RS, Pebesma E, Gomez-Rubio V (2013) Applied spatial data analysis with R, Second edition. Springer, New York, NY, http://www.asdar-book.org/

Diaz-Almela E, Arnaud-Haond S, Vliet MS, Alvarez E, Marba N, Duarte CM, Serrao EA (2007) Feed-backs between genetic structure and perturbation-driven decline in seagrass (Posidonia oceanica) meadows. Conserv Genet 8:1377-1391

Dorken ME, Barrett SCH (2003) Life-history differentiation and the maintenance of monoecy and dioecy in Sagittaria latifolia (Alismataceae). Evolution 57:1973-1988

Dorken ME, Barrett SCH (2004) Sex determination and the evolution of dioecy from monoecy in Sagittaria latifolia (Alismataceae). Proc R Soc Lond B 271:213-219

Dorken ME, Eckert CG (2001) Severely reduced sexual reproduction in northern populations of a clonal plant, Decodon verticillatus (Lythraceae). J Ecol 89:339-350

Dorken ME, Friedman J, Barrett SCH (2002) The evolution and maintenance of monoecy and dioecy in Sagittaria latifolia (Alismataceae). Evolution 56:31-41

Dorken ME, Mitchard ETA (2008) Phenotypic plasticity of hermaphrodite sex allocation promotes the evolution of separate sexes: an experimenal test of the sex-differential plasticity hypothesis using Sagittaria latifolia (Alismataceae). Evolution 62:971-978

Eckert CG, Dorken ME, Barrett SCH (2016) Ecological and evolutionary consequences of sexual and clonal reproduction in aquatic plants. Aquat Bot 135:46-61

Ellstrand NC, Roose ML (1987) Patterns of genotypic diversity in clonal plant species. Am J Bot 74:123-131

González-Martinez S, Gerber S, Cervera M, Martinez-Zapater J, Gil L, Alia R (2002) Seed gene flow and fine-scale structure in a Mediterranean pine (Pinus pinaster Ait.) using nuclear microsatellite markers. Theor Appl Genet 104:1290-1297

Hämmerli A, Reusch TBH (2003) Inbreeding depression influences genet size distribution in a marine angiosperm. Mol Ecol 12:619-629

Hardy OJ, Vekemans X (2002) SPAGeDi: a versatile computer program to analyse spatial genetic structure at the individual or population levels. Mol Ecol Notes 2:618-620

de Jager M, Kaphingst B, Janse EL, Buisman R, Rinzema SGT, Soons MB (2019) Seed size regulates plant dispersal distances in flowing water. J Ecol 107:307-317

Jombart T (2008) adegenet: a R package for the multivariate analysis of genetic markers. Bioinformatics 24:1403-1405 
Kalinowski ST, Taper ML, Marshall TC (2007) Revising how the computer program CERVUS accommodates genotyping error increases success in paternity assignment. Mol Ecol 16:1099-1106

Kamel SJ, Hughes AR, Grosberg RK, Stachowicz JJ (2012) Fine-scale genetic structure and relatedness in the eelgrass Zostera marina. Mar Ecol Prog Ser 447:127-137

Kenow KP, Gray BR, Lyon JE (2018) Flooding tolerance of Sagittaria latifolia and Sagittaria rigida under controlled laboratory conditions. River Res Appl 34:1024-1031

Kenow KP, Lyon JE (2009) Composition of the soil seed bank in drawdown areas of the navigation pool 8 of the Upper Mississippi River. River Res Appl 25:194-207

Kirk H, Paul J, Straka J, Freeland JR (2011) Long-distance dispersal and high genetic diversity are implicated in the invasive spread of the common reed, Phragmites australis (Poaceae), in northeastern North America. Am J Bot 98:1180-1190

Levin SA, Muller-Landau HC, Nathan R, Chave J (2003) The ecology and evolution of seed dispersal: a theoretical perspective. Annu Rev Ecol Evol Syst 34:575-604

Li W (2014) Environmental opportunities and constraints in the reproduction and dispersal of aquatic plants. Aquat Bot 118:62-70

Loh R, Scarano FR, Alves-Ferreira M, Salgueiro F (2015) Clonality strongly affects the spatial genetic structure of the nurse species Aechmea nudicaulis (L.) Griseb.(Bromeliaceae). Bot J Linn Soc 178:329-341

Loiselle BA, Sork VL, Nason J, Graham C (1995) Spatial genetic structure of a tropical understory shrub, Psychotria officinalis (Rubiaceae). Am J Bot 82:1420-1425

Nei M (1978) Estimation of average heterozygosity and genetic distance from a small number of individuals. Genetics 89:583-590

Pebesma EJ, Bivand RS (2005) Classes and methods for spatial data in R. R News 5 (2), https://cran.r-project.org/doc/Rnews/

Kemperman JA, Barnes BV (1976) Clone size in American aspens. Can J Bot 54:2603-2607

Pollux BJA, de Jong M, Steegh A, Ouborg NJ, van Groenendael JM, Klaassen M (2006) The effect of seed morphology on the potential dispersal of aquatic macrophytes by the common carp (Cyprinus carpio). Freshw Biol 51:2063-2071

Pollux BJA, de Jong M, Steegh A, Verbruggen E, van Groenendael JM, Ouborg NJ (2007) Reproductive strategy, clonal structure and genetic diversity in populations of the aquatic macrophyte Sparganium emersum in river systems. Mol Ecol 16:313-325

Pollux BJA, Santamaría L, Ouborg NJ (2005) Differences in endozoochorous dispersal between aquatic plant species, with reference to plant population persistence in rivers. Freshw Biol 50:232-242

Purves DW, Dushoff J (2005) Directed seed dispersal and metapopulation response to habitat loss and disturbance: application to Eichhornia paniculata. J Ecol 93:658-669 de Ridder F, Dhondt AA (1992) The demography of a clonal herbaceous perennial plant, the longleaved sundew Drosera intermedia, in different heathland habitats. Ecography 15: 129-143

Robinson RW, Boon PI, Sawtell N, James EA, Cross R (2008) Effects of environmental conditions on the production of hypocotyl hairs in seedlings of Melaleuca ericifolia (swamp paperbark). Aust $\mathbf{J}$ Bot 56:564-573

Santamaría L (2002) Why are most aquatic plants widely distributed? Dispersal, clonal growth and small-scale heterogeneity in a stressful environment. Acta Oecol 23:137-154

Sarkissian TS, Barrett SCH, Harder LD (2001) Gender variation in Sagittaria latifolia (Alismataceae): is size all that matters? Ecology 82:360-373

Schnittler M, Eusemann P (2010) Consequences of genotyping errors for estimation of clonality: a study on Populus euphratica Oliv. (Salicaceae). Evol Ecol 24:1417-1432

Schorg AJ, Romano SP (2018) Shallow and deep water aquatic vegetation potential for a midlatitude pool of the Upper Mississippi River System with drawdown. River Res Appl 34:310-316

Scofield DG, Schultz ST (2005) Mitosis, stature and evolution of plant mating systems: low- $\Phi$ and high- $\Phi$ plants. Proc R Soc Lond B 273:275-282

R Core Team (2019) R: a language and environment for statistical computing. R Foundation for Statistical Computing, Vienna, Austria

Tero N, Aspi J, Siikamäki P, Jäkäläniemi A (2005) Local genetic population structure in an endangered plant species, Silene tatarica (Caryophyllaceae). Heredity 94:478-487

Travis SE, Hester MW (2005) A space-for-time substitution reveals the long-term decline in genotypic diversity of a widespread salt marsh plant, Spartina alterniflora, over a span of 1500 years. J Ecol 93:417-430

Valière N (2002) GIMLET: a computer program for analysing genetic individual identification data. Mol Ecol Notes 2:377-379

Vekemans X, Hardy OJ (2004) New insights from fine-scale spatial genetic structure analyses in plant populations. Mol Ecol 13:921-935

Viana DS, Santamaría L, Michot TC, Figuerola J (2013) Migratory strategies of waterbirds shape the continental-scale dispersal of aquatic organisms. Ecography 36:430-438

Yakimowski SB, Barrett SCH (2014) Clonal genetic structure and diversity in populations of an aquatic plant with combined vs. separate sexes. Mol Ecol 23:2914-2928

Yakimowski SB, Rymer PD, Stone H, Barrett SCH, Dorken ME (2009) Isolation and characterization of 11 microsatellite markers from Sagittaria latifolia (Alismataceae). Mol. Ecol Res 9:579-581 